\title{
A typhlopid hotspot in the tropics: increased blindsnake diversity in the Kimberley region of Western Australia with the description of a new Anilios species (Serpentes:Typhlopidae)
}

\author{
Ryan J. Ellis \\ Department of Terrestrial Zoology, Western Australian Museum, Locked Bag 49, Welshpool DC, \\ Western Australia 6986, Australia. Biologic Environmental Survey, 24-26 Wickham St, East Perth, \\ Western Australia 6004, Australia. \\ Email: ryan.ellis@museum.wa.gov.au
}

\begin{abstract}
The blindsnake genus Anilios is the most speciose genus of Australian snakes and represents one of the most species rich genera of snakes globally. Morphological and molecular studies continue to highlight further diversity within the genus, suggesting true species diversity is far greater than currently known. A morphologically distinct new species of blindsnake, Anilios vagurima sp. nov., is described from a single specimen collected from Mornington Wildlife Sanctuary in the Kimberley region of Western Australia in 2006. The species differs from all other Anilios species in possessing 22 midbody scale rows, 542 dorsal body scales, head moderately trilobed in dorsal view, rounded in profile view, and a unique configuration of the nasal cleft. The cleft originates at the second supralabial and arcs anterodorsally to the nostril and then posterodorsally to lie nearly parallel to rostral-nasal suture within the apex of nasal scale, where it is clearly visible in dorsal view.
\end{abstract}

KEYWORDS: Reptilia, Squamata, Scolecophidia, taxonomy, morphology

urn:Isid:zoobank.org:pub:B1A629D4-77F1-4105-ACFC-8C53D7AB3A4D

\section{INTRODUCTION}

The Kimberley region of north-western Australia supports a highly diverse fauna of reptiles and amphibians, including many regionally endemic taxa (How and Cowan 2006; Slatyer et al. 2007; Powney et al. 2010; Doughty 2011; Doughty et al. 2012a; Palmer et al. 2013; Pepper and Keogh 2014; Meiri 2016). Despite relatively poor sampling across the region, ongoing collections and detailed examinations of museum specimens, particularly in association with molecular genetic techniques, continue to lead to the discovery and description of new reptile taxa in the region (Bauer and Doughty 2012; Doughty et al. 2012b; Doughty et al. 2014; Oliver et al. 2014a; Oliver et al. 2014b; Maddock et al. 2015; Ellis 2016; Oliver et al. 2016).

The Australian blindsnakes (genus Anilios Gray, 1845) constitute the most diverse snake genus in Australia, with 46 currently recognised species (Uetz et al. 2019). With 47 species recognised worldwide, Anilios is also the most species rich genus in the family Typhlopidae and ranks $10^{\text {th }}$ among the most diverse snake genera globally. However, molecular and morphological studies have indicated the true species diversity within the genus remains largely underestimated (Marin et al. 2013; Ellis 2016; Ellis et al. 2017). The Kimberley region supports the greatest diversity of Anilios species, with 11 currently recognised species, including five endemics. Of these endemics, four were described from only a single specimen (A. howi (Storr, 1983), $A$. micromma (Storr, 1981), A troglodytes (Storr, 1981) and A. yampiensis (Storr, 1981)) and the other from two specimens (A. zonula Ellis, 2016), all with few or no additional specimens collected since being described.

I here present the morphology of a unique Anilios specimen from the Kimberley region of Western Australia and, based on diagnostic morphological characteristics, describe it as a new species.

\section{MATERIAL AND METHODS}

Nomenclature of head scales follows Waite (1918) and Storr (1981) with the exception of the median dorsal series of scales, which follows Wallach (2003). Total dorsal scale (TDS) counts were taken from the frontal scale to the last scale overlapping the terminal caudal scale, inclusive. Subcaudal scales (SCS) were counted from the first scale posterior to the vent to the last scale 
overlapping the terminal caudal scale, inclusive. Dorsal body scales (DBS), excluding tail scales, were calculated by subtracting SCS from TDS. Midbody scale rows (MBSR) were counted approximately mid snout-vent length (SVL). Supralabial imbrication pattern follows Wallach (1993). Anal scales are defined as the number of ventral body scales overlapping the vent anteriorly. SVL and tail length (TailL) were measured with a metal ruler to the nearest $0.5 \mathrm{~mm}$, from tip of snout to anterior margin of vent for SVL and from posterior margin of vent to tail tip for TailL. Midbody width (MBW) was measured to nearest $0.1 \mathrm{~mm}$ using a digital vernier caliper at approximately mid SVL. Where possible, sex of specimens was identified from everted hemipenes, presence of eggs, or determined by examination of internal reproductive organs.

Comparisons were made with museum material (including type specimens) from the collections of the Western Australian Museum, Perth (WAM; where the holotype is located), Museum and Art Galleries of the Northern Territory, Darwin (NTM) and Queensland Museum, Brisbane (QM).

\section{TAXONOMY}

\section{Family Typhlopidae Merrem, 1820}

\section{Genus Anilios Gray, 1845}

\section{TYPE SPECIES}

Anilios australis Gray, 1845, by subsequent designation by Stejneger (1904).

\section{Anilios vagurima sp. nov.}

Mornington Blindsnake

Figures 1-2

urn:Isid:zoobank.org:act:42E651A8-C68F-43B5-A189174DB9F98740

\section{MATERIAL EXAMINED}

\section{Holotype}

Australia: Western Australia: WAM R163524, adult male collected on 21 October 2006, from Mornington Sanctuary, south central Kimberley region, Western Australia, Australia $\left(-17.0338^{\circ} \mathrm{S}, 126.6537^{\circ} \mathrm{E}\right)$. Collector unknown, donated to the WAM by R. Lloyd, 21 August 2008. Fixative unknown, stored in $70 \%$ ethanol solution at WAM.

\section{DIAGNOSIS}

A moderately slender and elongate Anilios to approximately $325 \mathrm{~mm}$. Distinguished from all other congeners by a combination of midbody scales in 22 rows, 557 total dorsal scales, 542 dorsal body scales; snout moderately trilobed in dorsal view, bluntly rounded and elongate in profile; rostral scale narrowly bell-shaped, widest anteriorly at rostral-nasal suture, $\sim 40 \%$ of head width, with posterior edge terminating well before eye line; nasal scale partially divided, offset nostril positioned slightly closer to rostral than preocular; nasal cleft originating at the second supralabial and arcs anterodorsally to the nostril and then posterodorsally to lie nearly parallel to rostral-nasal suture within the apex of nasal scale, where it is clearly visible in dorsal view; and contrasting dorsal and ventral colouration.

\section{DESCRIPTION OF THE HOLOTYPE (WAM R163524)}

Adult male, measurements and counts: SVL 324.5 mm; TailL $4.4 \mathrm{~mm}$ (1.4\% of SVL); MBW $3.8 \mathrm{~mm}$; TDS 566; DBS 552; MBSR 22; SCS 14; anal scales five; supralabials four; infralabials four; rostral length 2.1 $\mathrm{mm}$; rostral width $1.6 \mathrm{~mm}$.

Head in dorsal view moderately trilobed and stout, widest just posterior to eyes, head in profile narrowly rounded and elongate, snout bluntly rounded, anterior most point of snout just above nostril; anteriormost point of lower jaw posterior to nostril; rostral longer than wide $(\sim 2.1 \mathrm{~mm}$ long $\times 1.6 \mathrm{~mm}$ wide), $\sim 40 \%$ of head width, narrowly bell-shaped, widest at anteriorly at rostral-nasal suture, narrowing posteriorly, anterior protrusion of rostral from rostral-nasal suture shallowly concave, posterior edge of rostral scale deeply concave, not reaching eyeline; frontal wider than long, $\sim 1.5$ times wider than long, $\sim 3$ times the area of postfrontal; postfrontal smaller than frontal and interparietal, wider than long, $\sim 1.5$ times wider than long; interparietal wider than long, $\sim 2$ times wider than long, $\sim 1.5$ times the size of postfrontal in area; supraoculars equal to frontal in area, widely separated by postfrontal scale, separation $\sim$ one-third of postfrontal width; parietals slightly smaller than supraoculars in area, length slightly shorter than supraoculars, width equal to supraoculars, length, widely separated by interparietal, separation $\sim$ one-quarter width of interparietal; nasal scale narrower than high, widest just above nostril, partially divided vertically by nasal cleft, widely separated by frontal, separation $\sim$ one-third frontal width, greater than supraocular and interparietal separation; preocular much narrower than high, widest just above nostril, $\sim$ one-half the size of nasal in area; ocular narrower than high, $\sim 1.25$ times the size of preocular, shallowly wedged between third and fourth supralabial, in contact with preocular, supraocular, parietal, upper and lower postoculars, third and fourth supralabials; eyes small and rounded, equal to size of nostril, inconspicuous, positioned under ocular scale in apex of scale; nostrils inferior, not visible in dorsal view, slightly anteriorly offset to middle of nasal scale, slightly closer to preocular than rostral suture of nasal (appears closer to rostral in lateral view); nasal cleft originates from antero-dorsal edge of second supralabial, extends dorsally and anteriorly gradually to postero-ventral edge of nostril, from nostril extends dorsally and posteriorly, 


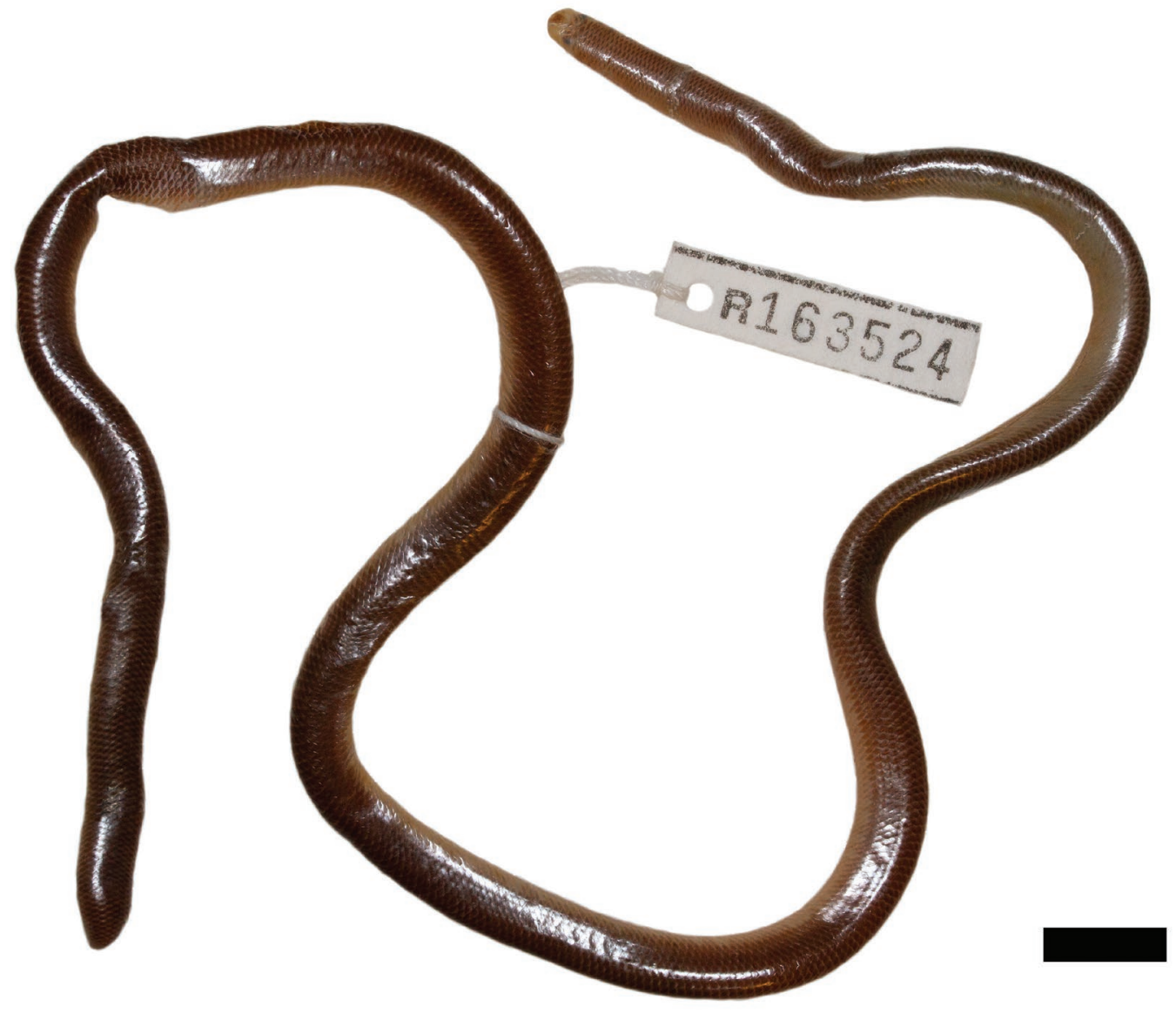

FIGURE 1 Holotype of Anilios vagurima sp. nov. (WAM R163524). Scale bar $=10 \mathrm{~mm}$.

nearly parallel to rostral-nasal suture, to terminate near apex of nasal scale, approximately midway between rostral and preocular scales, slightly closer to rostral than preocular, cleft termination point and dorsal half of nasal cleft extension from nostril visible in dorsal view; supralabials four; first supralabial smallest and overlapped by nasal; second supralabial $\sim 3.0-3.5$ times the size of the first, overlapped by nasal and preocular, overlapping third supralabial; third supralabial $\sim 2.5$ times the size of second, overlapped by preocular and overlapping ocular and fourth supralabial; fourth supralabial largest, $\sim 2$ times the size of third, overlapped by third supralabial and ocular, overlapping lower postocular and 4-5 body scales, posterior edge extends beyond posterior edge of ocular; supralabial imbrication pattern consistent with type T-III sensu Wallach (1993); mental scale $\sim 2$ times wider than long; postmental requal in size, widely separating first infralabials; infralabials four, first and second smallest, third $\sim 1.5$ times larger, fourth largest, $\sim 1.25$ times the size of third.

Body width constant between head and tail, 3.8 $\mathrm{mm}$, tapers slightly towards head and tail; tail short (4.4 mm), 1.4\% of SVL, tapering gradually from vent to bluntly rounded point, terminal tail scale not present in specimen (scale appears to have become detached); body scales $\sim 2$ times wider than long, smooth and imbricate, in contact with or narrowly separated from flanking body scales, posterior edge overlapping anterior portion of proceeding scale; anal scales five, equal to one-half the size of preceding body scales.
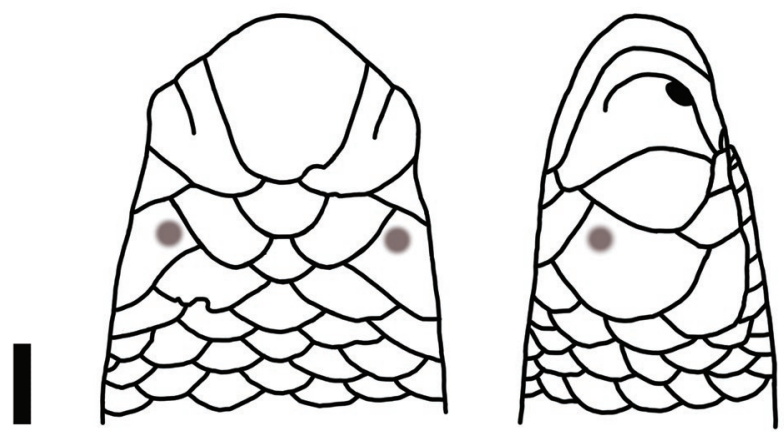

FIGURE 2 Head scalation of Anilios vagurima sp. nov. holotype (WAM R163524) in dorsal, ventral and lateral view. Scale bar $=1 \mathrm{~mm}$. 


\section{Colouration}

In preservative, contrasting dorsal and ventral colouration along body length, dorsum light brownish, scales dark with pale anterior edge, 7-11 body scales wide, widest at midbody, with abrupt lateral transition to pale tan-coloured ventrum; snout pale with darker patches. No known photos in life.

\section{DISTRIBUTION}

The species is known only from the type locality on Mornington Wildlife Sanctuary in the east Kimberley of Western Australia (Figure 3).

\section{HABITAT}

The type specimen was collected from open savannah woodland habitat. Habitat was characterised by a canopy dominated by Eucalyptus brevifolia and occasionally other trees (including E. opaca, E. tectifica, Corymbia grandifolia and $C$. polycarpa), over a sparse shrub cover $(<10 \%)$ comprising mixed small to medium shrubs (including Carissa spinarum, Dodonia oxyptera, Brachychiton diversifolius and Persoonia sp.) and patchy cover of mixed tussock grasses $(\sim 30-60 \%)$, dominated by Sehima nervosum and other grasses (including Aristida sp., Chrysopogon fallax, Heteropogon contortus, Sorghum timorense and Themeda triandra), on a compacted red-brown clay-loam substrate with sparsely scattered termite mounds (Figure 4A).
The description above is for the habitat around the time the type specimen was collected in 2006 during a period the site was unburnt; however, fires occurred at the site on numerous occasions, including in 2009 and 2018 (Figure 4B). Following burn events, the habitat above differs in that understory vegetation is largely void preceding natural regrowth of shrubs and grasses, which may result in structural and density changes over time during periods of regrowth at the site. It is unknown if, or how, the occurrence of fire may influence the occurrence of the species at the site.

\section{ETYMOLOGY}

The specific epithet vagurima (pronounced vah-gooree-mah, with accent on the second syllable) is formed from the Latin words vagus (wandering, stray) and rima (cleft, fissure), as in 'wandering-cleft', in reference to the wandering path and termination point of the nasal cleft diagnostic for the species. Used as a noun in apposition.

\section{COMPARISON WITH OTHER SPECIES}

Anilios vagurima sp. nov. differs from 36 of the 46 native Australian Anilios species and introduced Indotyphlops braminus by its number of MBSR (22 vs. 16, 18, 20 or 24), which does not vary within any Anilios species. Of the ten congeners with $22 \mathrm{MBSR}$ (A. australis, A. bicolor, A. endoterus, A. hamatus, A. kimberleyensis, A. nigrescens, A. pilbarensis, A. robertsi, A. torresianus,

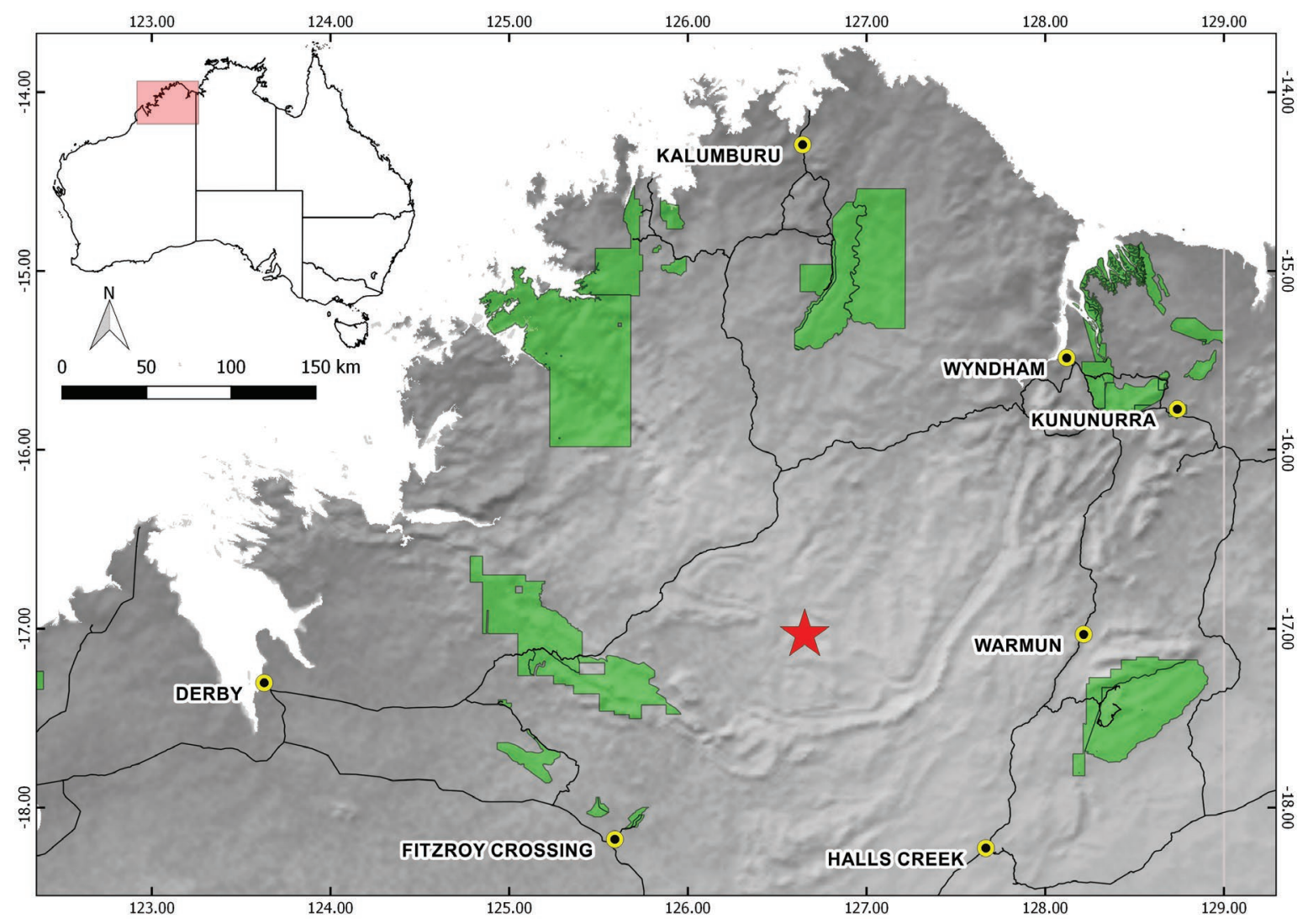

FIGURE 3 Distribution of Anilios vagurima sp. nov. (red star) within Kimberley region of Western Australia. Grey shading represents topography, green shading indicates conservation reserves or National Parks and black lines represent major roads and tracks 

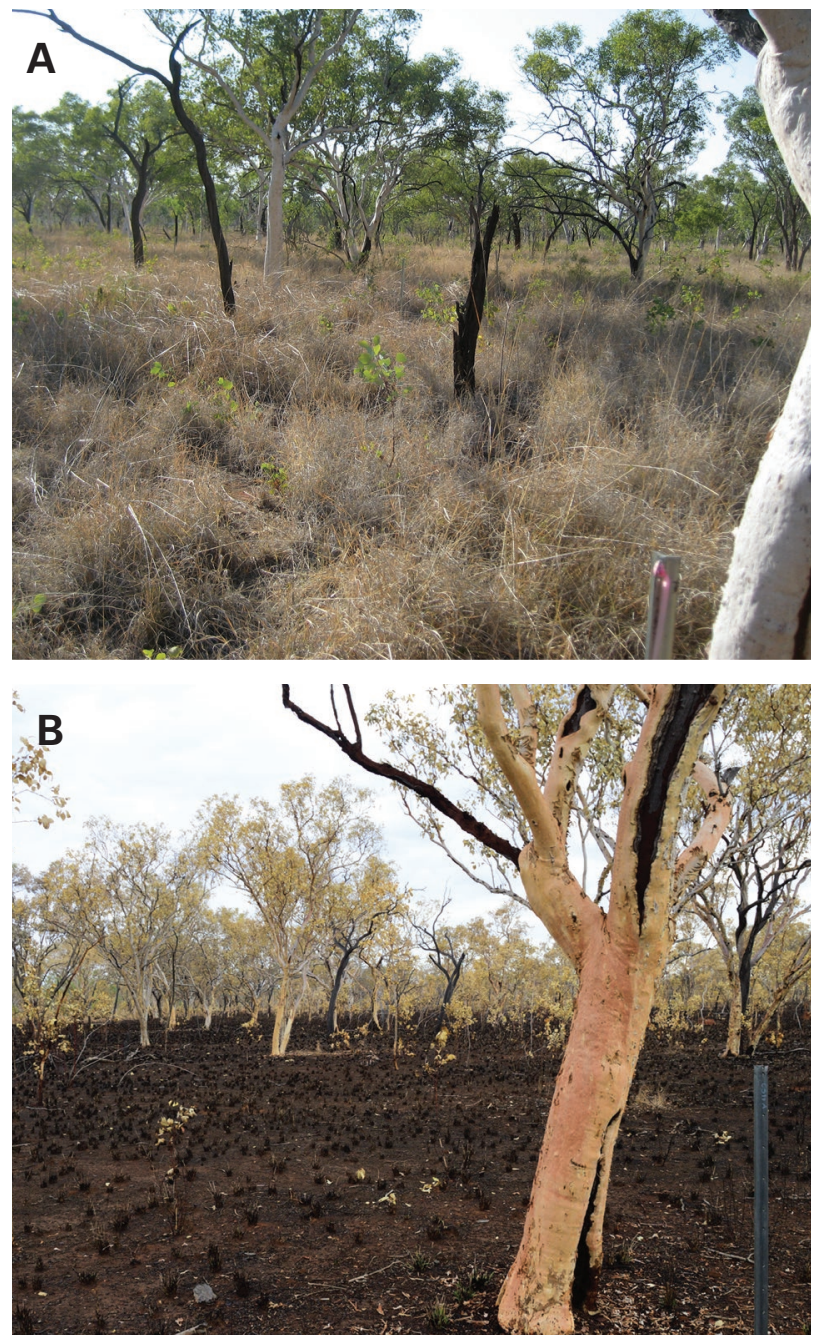

FIGURE 4 Type locality habitat of Anilios vagurima sp. nov. at Mornington Wildlife Sanctuary, Kimberley region, Western Australia: A) In unburnt condition. Photo taken 6 October 2008 (photograph: Australian Wildlife Conservancy); B) Following 2018 burn. Photo taken 6 November 2018 (photograph: Melissa Bruton, Australian Wildlife Conservancy).

A. troglodytes), A. vagurima can be diagnosed by a combination of the following; DBS 552 (vs. $<525$ in $A$. kimberleyensis or $<450$ in A. australis, A. bicolor, $A$. endoterus, A. hamatus, A. kimberleyensis, A. nigrescens, A. pilbarensis and $A$. torresianus), snout moderately trilobed in dorsal view (vs. weakly trilobed in $A$. endoterus, A. hamatus and A. pilbarensis or rounded in A. australis, $A$. kimberleyensis, $A$. nigrescens, $A$. robertsi, A. torresianus and $A$. troglodytes) and narrowly rounded in profile (vs. angular in A. bicolor, A. endoterus, $A$. hamatus or beaked in $A$. pilbarensis), rostral scale bellshaped, $\sim 40 \%$ of head width (vs. broadly to narrowly subovate, circular or elliptical in A. australis, $A$. bicolor, A. endoterus, $A$. hamatus, A. kimberleyensis, $A$. nigrescens, $A$. pilbarensis, $A$. robertsi, $A$. torresianus, $A$. troglodytes), nasal scale partially divided vertically by nasal cleft (vs. divided in A. troglodytes and sometimes divided in $A$. endoterus) and unique origin (second supralabial vs. preocular in $A$. endoterus, A. nigrescens and $A$. pilbarensis or sometimes at junction of first and second supralabial in A. australis, A. hamatus and $A$. torresianus), path from nostril (extending dorso-posterior direction, nearly parallel to rostral-nasal suture vs. anterior or dorso-anterior direction towards rostral in A. australis, A. bicolor, A. endoterus, A. hamatus, $A$. nigrescens, $A$. pilbarensis, $A$. robertsi) and termination point (apex of nostril scale vs. nostril, midway between nostril and rostral or at rostral in A. australis, A. bicolor, A. endoterus, $A$. hamatus, A. nigrescens, $A$. pilbarensis, $A$. robertsi and $A$. troglodytes) of nasal cleft, and nasal cleft clearly visible in dorsal view (vs. only just in $A$. robertsi or not visible in $A$. australis, $A$. bicolor, $A$. endoterus, A. hamatus and A. pilbarensis).

Of the 11 Anilios species known to occur in the Kimberley region of Western Australia, A. vagurima can be diagnosed from nine (A. diversus, A. grypus, A. guentheri, A. howi, A. ligatus, A. micromma, $A$. unguirostris, A. yampiensis and $A$. zonula) in having 22 MBSR (vs. 18, 20 or 24). Of the two species in the region with 22 MBSR (A. kimberleyensis and A. troglodytes), $A$. vagurima differs from $A$. kimberleyensis in having moderately trilobed snout in dorsal view (vs. rounded), narrowly rounded in profile (vs. bluntly rounded), higher number of DBS (542 vs. <510), path of nasal cleft upwards and towards rostral slightly, almost parallel to rostral-nasal suture, terminating midway between rostral and preocular (vs. upwards and backwards and gradually closer to rostral-nasal suture towards terminus, with slightly recurved terminus towards rostral, terminating closer to rostral than preocular), nasal suture closest to rostral approximately midway between nostril and terminus (vs. at cleft terminus). It differs from $A$. troglodytes in having moderately trilobed snout in dorsal view (vs. rounded), fewer DBS (542 vs. >580), path of nasal cleft from nostril extending upwards and towards rostral slightly, almost parallel to rostral-nasal suture, terminating $\sim$ midway between rostral and preocular (vs. upwards and forwards to, or nearly to, rostral scale).

Within the Kimberley region of Western Australia, Anilios vagurima sp. nov. is most similar in appearance to A. kimberleyensis and A. unguirostris in general appearance. The type specimen of $A$. vagurima sp. nov. keys out to $A$. kimberleyensis using keys provided in Cogger (2018) and Storr et al. (2002); however, it is clearly distinguished from $A$. kimberleyensis as discussed above. With $A$. unguirostris, $A$. vagurima sp. nov. shares a moderately slender body form, contrasting dorsal and ventral colouration along body length and moderately trilobed snout in dorsal view; however, it differs in having fewer midbody scale rows (22 vs. 24), rounded snout lacking hook in profile (vs. hooked), nasal cleft originating from second supralabial (vs. first), from nostril extending upwards and backwards to top of head, parallel to rostral scale (vs. upwards and forwards to or nearly to rostral) and clearly visible from above (vs. not or scarcely). 


\section{REMARKS}

Placement of A. vagurima sp. nov. in the genus Anilios is based largely on geographic distribution as Anilios is the only typhlopid genus known to be represented in Australia, apart from the introduced Indotyphlops braminus. Diagnostic characteristics to differentiate Anilios and its former senior synonym, Ramphotyphlops, presented by Hedges et al. (2014) and Pyron and Wallach (2014) show shared characters and significant overlap with each other, resulting in difficulty of generic placement for new taxa. Species described on the basis of morphological data alone, A. insperatus Venchi, Wilson \& Borsboom, 2015, A. fossor Shea, 2015 and $A$. zonula Ellis, 2016, have been allocated to Anilios solely on geographic grounds, whereas A. systenos Ellis \& Doughty in Ellis et al., 2017 and A. obtusifrons Ellis \& Doughty in Ellis et al., 2017 were assigned to the genus based on phylogenetic relationships inferred from molecular data (Shea 2015; Venchi et al. 2015; Ellis 2016; Ellis et al. 2017).

Like many other Anilios species only know from the type or very few specimens in the Kimberley region, $A$. vagurima sp. nov. is Data Deficient under the IUCN Red List assessment criteria (IUCN Standards and Petitions Subcommittee 2017) due to the absence of sufficient information on the species extent of occurrence, area of occupancy, population information and potential threats to undertake a full assessment and determine the species conservation status with certainty.

\section{DISCUSSION}

The description of Anilios vagurima sp. nov. increases the number of species in the genus Anilios to 48, 47 of which are endemic to Australia, making it the equal 9th (tied with elapid genus Hydrophis and viperid genera Crotalus and Trimeresurus) most species rich snake genus globally. It also highlights the high diversity of blindsnakes within the already diverse Kimberley region, with 12 species $(\sim 25.5 \%)$ now known from the region, 13 including the introduced I. braminus. This diversity is currently unparalleled by any other region across Australia with the nearest (the Northern Territory's Top End and Queensland's Cape York regions currently only having nine species each. This, however, may be attributed to limited sampling of blindsnakes within these regions.

Although not all species occurring in the Kimberley were included, Marin et al. (2013) identified high levels of undescribed diversity and multiple cryptic taxa within existing species where more than a single sample was included (i.e., A. diversus, A. guentheri, $A$. kimberleyensis, $A$. ligatus and $A$. unguirostris), despite a historically limited sampling effort across the region in comparison to some others (i.e., Pilbara and south-west of Western Australia) (Ellis 2016).

The description of yet another blindsnake species based on morphology alone, and without supporting molecular data, further supports the highly underestimated species diversity occurring in Australian blindsnakes suggested by Marin et al. (2013). On the basis that four of the six most recently described Anilios species were described on morphology alone, recent descriptions may also be indicative of true diversity being greater than the $207-341 \%$ (based on 27 nominal taxa samples) suggested by Marin et al. (2013).

\section{ACKNOWLEDGEMENTS}

I thank R. Lloyd for lodging the type specimen of A. vagurima sp. nov. with the WAM and for further information on the type specimen and type locality, M. Bruton (Australia Wildlife Conservancy) for photographs of and additional habitat information and history on the type locality, A. Amey (QM) and G. Dally (NTM) for making specimens in their respective collections available for this study, A.M. Bauer (Villanova University) and P. Doughty (WAM) for various technical discussions and suggestions for the manuscript. I thank P. Couper (QM) and A.M. Bauer (Villanova University) for providing reviews and constructive criticism on the manuscript prior to publication.

\section{REFERENCES}

Bauer, A.M. and Doughty, P. (2012). A new bent-toed gecko (Squamata: Gekkonidae: Cyrtodactylus) from the Kimberley region, Western Australia. Zootaxa 3187: 32-42.

Cogger, H.G. (2018). Reptiles and Amphibians of Australia, updated 7th edition. CSIRO Publishing, Collingwood.

Doughty, P. (2011). An emerging frog diversity hotspot in the northwest Kimberley of Western Australia: another new frog speces from the high rainfall zone. Records of the Western Australian Museum 26: 209-216.

Doughty, P., Palmer, R., Cowan, M. and Pearson, D.J. (2012a). Biogeographic patterns of frogs of the Kimberley islands, Western Australia. Records of the Western Australian Museum, Supplement 81: 109-124. doi: 10.18195/issn.0313122x.81.2012.109-124.

Doughty, P., Palmer, R., Sistrom, M.J., Bauer, A.M. and Donnellan, S.C. (2012b). Two new species of Gehyra (Squamata: Gekkonidae) geckos from the north-west Kimberley region of Western Australia. Records of the Western Australian Museum 27: 117-134. doi: 10.18195/ issn.0312-3162.27(2).2012.117-134.

Doughty, P., Kealley, L., Fitch, A. and Donnellan, S.C. (2014). A new diminutive species of Varanus from the Dampier Peninsula, western Kimberley region, Western Australia. Records of the Western Australian Museum 29: 128-140. doi: 10.18195/issn.0312-3162.29(2).2014.128-140.

Ellis, R.J. (2016). A new species of blindsnake (Scolecophidia: Typhlopidae: Anilios) from the Kimberley region of Western Australia. Herpetologica 72: 271-278.

Ellis, R.J., Doughty, P., Donnellan, S.C., Marin, J. and Vidal, N. (2017). Worms in the sand: Systematic revistion of the Australian blindsnake Anilios leptosoma (Robb, 1972) species complex (Squamata: Scolecophidia: Typhlopidae) from the Geraldton Sandplain, with description of two new species. Zootaxa 4323: 1-24. doi: 10.11646/zootaxa.4323.1.1.

Gray, J.E. (1845). Catalogue of the Specimens of Lizards in the Collection of the British Museum. Trustees of the British Museum/Edward Newman, London. 
Hedges, S.B., Marion, A.B., Lipp, K.M., Marin, J. and Vidal, N. (2014). A taxonomic framework for typhlopid snakes from the Caribbean and other regions (Reptilia, Squamata). Caribbean Herpetology 49: 1-61.

How, R.A. and Cowan, M.A. (2006). Collections in space and time: geographical patterning of native frogs, mammals and reptiles through a continental gradient. Pacific Conservation Biology 12: 111-133.

IUCN Standards and Petitions Subcommittee. (2017). Guidelines for Using the IUCN Red List Categories and Criteria. International Union for Conservation of Nature [IUCN], Gland, Switzerland. Available at: http://www. iucnredlist.org/documents/RedListGuidelines.pdf

Maddock, S.T., Ellis, R.J., Doughty, P., Smith, L.A. and Wüster, W. (2015). A new species of death adder (Acanthophis: Serpentes: Elapidae) from north-western Australia. Zootaxa 4007: 301-326. doi: 10.11646/zootaxa.4007.3.1.

Marin, J., Donnellan, S.C., Hedges, B., Puillandre, N., Aplin, K.P., Doughty, P., Hutchinson, M.N., Couloux, A. and Vidal, N. (2013). Hidden species diversity of Australian burrowing snakes (Ramphotyphlops). Biological Journal of the Linnean Society 110: 427-441. doi: 10.2307/1563076.

Meiri, S. (2016). Small, rare and trendy: traits and biogeography of lizards described in the 21st century. Journal of Zoology 299: 251-261. doi: 10.1111/jzo.12356.

Merrem, B. (1820). Versuch eines Systems der Amphibien. J.C. Krieger, Marburg.

Oliver, P.M., Couper, P.J. and Pepper, M. (2014a). Independent transitions between monsoonal and arid biomes revealed by systematic revision of a complex of Australian geckos (Diplodactylus: Diplodactylidae). PLoS ONE 9: e111895. doi: 10.1371/journal.pone.0111895.

Oliver, P.M., Laver, R.J., Melville, J. and Doughty, P. (2014b). A new species of velvet gecko (Oedura: Diplodactylidae) from the limestone ranges of the southern Kimberley, Western Australia. Zootaxa 3873: 49-61. doi: 10.11646/ zootaxa.3873.1.4.

Oliver, P.M., Bourke, G., Pratt, R.C., Doughty, P. and Moritz, C. (2016). Systematics of small Gehyra (Squamata: Gekkonidae) of the southern Kimberley, Western Australia: redescription of G. kimberleyi Börner \& Schüttler, 1983 and description of a new restricted range species. Zootaxa 4107 : 49-64. doi: 10.11646/zootaxa.4107.1.2

Palmer, R., Pearson, D.J., Cowan, M.A. and Doughty, P. (2013). Islands and scales: a biogeographic survey of reptiles on Kimberley islands, Western Australia. Records of the Western Australian Museum, Supplement 81: 183-204. doi: 10.18195/issn.0313-122x.81.2013.183-204.
Pepper, M. and Keogh, J.S. (2014). Biogeography of the Kimberley, Western Australia: a review of landscape evolution and biotic response in an ancient refugium. Journal of Biogeography 41: 1143-1455. doi: 10.1111/ jbi.12324.

Powney, G.D., Grenyer, R., Orme, C.D.L., Owens, I.P.F. and Meiri, S. (2010). Hot, dry and different: Australian lizard richness is unlike that of mammals, amphibians and birds. Global Ecology and Biogeography 19: 386-396.

Pyron, R.A. and Wallach, V. (2014). Systematics of the blindsnakes (Serpentes: Scolecophidia: Typhlopoidea) based on molecular and morphological evidence. Zootaxa 3829: 1-81. doi: 10.11646/zootaxa.3829.1.1.

Shea, G.M. (2015). A new species of Anilios (Scolecophidia: Typhlopidae) from central Australia. Zootaxa 4033: 103116. doi: 10.11646/zootaxa.4033.1.5.

Slatyer, C., Rosauer, D. and Lemckert, F. (2007). An assessment of endemism and species richness patterns in the Australian anura. Journal of Biogeography 34: 583-596.

Stejneger, L. (1904). The herpetology of Porto Rico. Annual Reports of the United States National Museum 1902: 549-724.

Storr, G.M. (1981). The genus Ramphotyphlops (Serpentes: Typhlopidae) in Western Australia. Records of the Western Australian Museum 9: 235-371.

Storr, G.M. (1983). A new Ramphotyphlops (Serpentes: Typhlopidae) from Western Australia. Records of the Western Australian Museum 10: 315-317.

Storr, G.M., Smith, L.A. and Johnstone, R.E. (2002). Snakes of Western Australia. Western Australian Museum, Perth, Australia.

Uetz, P., Freed, P. and Hošek, J. (2019). The Reptile Database. Available at: http://www.reptile-database.org/

Venchi, A., Wilson, S.K. and Borsboom, A.C. (2015). A new blind snake (Serpentes: Typhlopidae) from an endangered habitat in south-eastern Queensland, Australia. Zootaxa 3990: 272-278. doi: 10.11646/zootaxa.3990.2.7.

Waite, E.R. (1918). Review of the Australian Blind Snakes (Family Typhlopidae). Records of the South Australian Museum 1: 1-34.

Wallach, V. (1993). The supralabial imbrication pattern of the Typhlopoidea (Reptilia: Serpentes). Journal of Herpetology 27: 214-218. doi: 10.2307/1564940.

Wallach, V. (2003). Scolecophidia miscellanea. Hamadryad 27: $222-240$

MANUSCRIPT RECEIVED 13 MARCH 2019; ACCEPTED 16 SEPTEMBER 2019 